\title{
Preliminary Study on Various Shaped Models of Delivery valve in Hydraulic Ram Pump - Experimental Results
}

\author{
Made Suarda ${ }^{1,2, *}$, I Gusti Bagus Wiajaya Kusuma ${ }^{1}$, Made Sucipta $^{1}$, and Ainul Ghurri ${ }^{1}$ \\ ${ }^{1}$ Department of Mechanical Engineering, University of Udayana, Badung-Bali 80362, Indonesia. \\ ${ }^{2}$ Doctoral Study Program of Engineering Science, University of Udayana, Denpasar-Bali 80225, Indonesia. \\ *made.suarda@unud.ac.id
}

\begin{abstract}
Four shaped models of delivery valve had been investigated and compared to improve performance of a hydraulic ram. Hydraulic ram pumps have been constructed and operated. Most of them built locally using steel pipe fittings that commercially accessible in the market rather than factory-made one. These have assisted inhabitants in rural or hilly area where water sources available for water supply services or irrigations. However, the major problem challenged by the public was on designing and repairing of the impulse and delivery valves of the pumps. Performance of the pumps are affected predominantly by the both valves. One characteristic of the valves is their shape. Considered on the characteristics of the fluid flow through surface of plate and sphere object are different on the pattern and losses. Therefore, investigation is necessitated to find a proper shape of the delivery valve for enhancing the performance of the pump. In this research four valve models were experimented to assess the hydraulic ram pump performance on varies delivery heads. The results show that the sphere model of the delivery valve offered the best efficiency, then followed by the membrane, the half-sphere and the flat delivery valve models. However, the rounded model: sphere and half-sphere delivery valve model were facing obstructions in implementation for a high delivery head.
\end{abstract}

Index Terms - Delivery valve, hydraulic ram, flat valve, membrane valve, sphere valve, half-sphere valve.

\section{INTRODUCTION}

A hydraulic ram pump is a mechanism which apply an appropriate technology for pumping water from lower to higher elevation. Basically, the construction of the pump is simple, it is equipped with a couple one-way direction valves that well-known as waste and delivery valves. The both valves mechanism triggered a high pressure surge or water hammer because of the waste valve closing suddenly then a fraction of the source water transmitted to higher altitude [1]. The pump is driven by hydropower itself therefore there is not any fuels or electricity consumed. It is fully a renewable machine [2]. Although since 1776 the pump was invented by Joseph Michel Montgolfier, and had been momentarily popular in a couple decades, then it respected obsolescent with the broad accessibility of electricity [3]. It is also environmental friendly and required minimal cost of construction and operation. The hydraulic ram can be installed in remote area to supply water in between different altitude at constant flow rate. It is completely green, and in accordance with the principles of sustainable development. Therefore, it is interested to develop in energy crisis faced today.

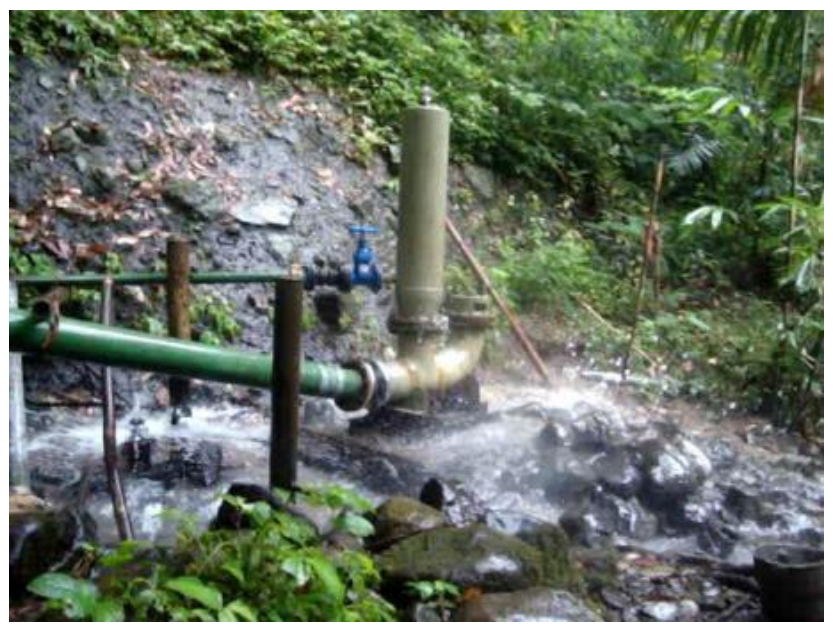

Fig. 1. Hydraulic ram implementation.

Recently, when the energy crisis struck the world and the renewable energy is concerned, the hydraulic rams were interested due to its practical installation in remote areas of developing regions, including in Indonesia. In the present study, the hydraulic rams were planned, fabricated and analyzed [4]. This device could be utilized for the supply of fresh water in some areas for daily household and irrigation. For instance, it was implemented for irrigation of lands in 
Northen area of Thailand [5]. In addition, the authors have been designed, constructed and installed fours hydraulic ram pumps on hilly regions in Bali province of Indonesia for a clean water supply and irrigation. For instance, a big size of hydraulic ram had implemented the pump for transmitting a river water for water supply system in Tabanan district of Bali province [6], as shown in Fig. 1. Moreover, in 2019, it has been implemented for academic tourism destination at Tukad Unda in Klungkung area of Bali province.

A hydraulic ram system comprise of water supply unit, the pump and delivery unit as shown in Fig. 2. Then, detail of components of the pump was presented as in Fig. 3.

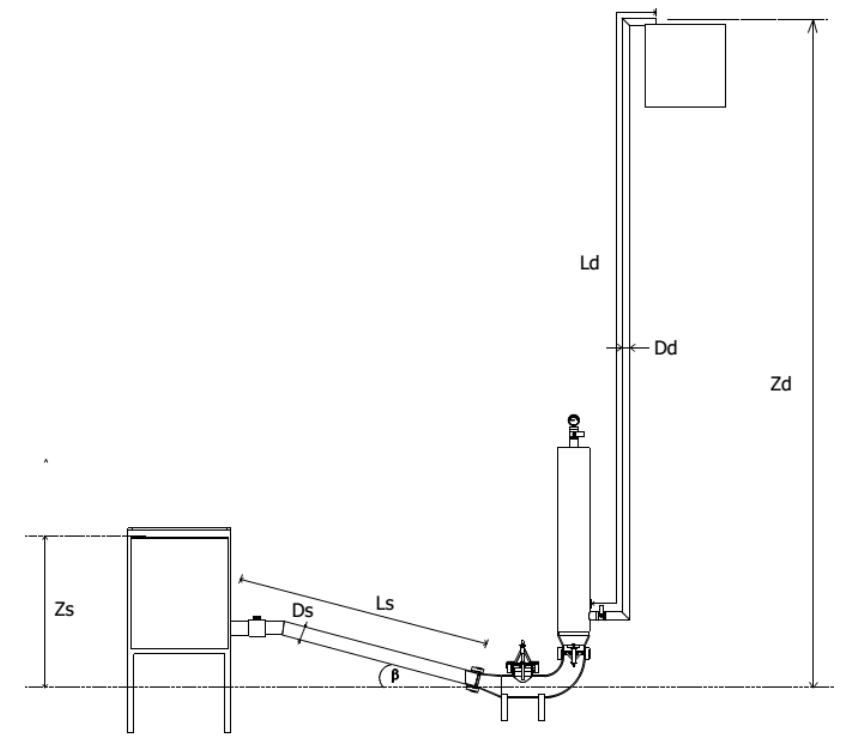

Fig. 2. Schema of hydraulic ram system

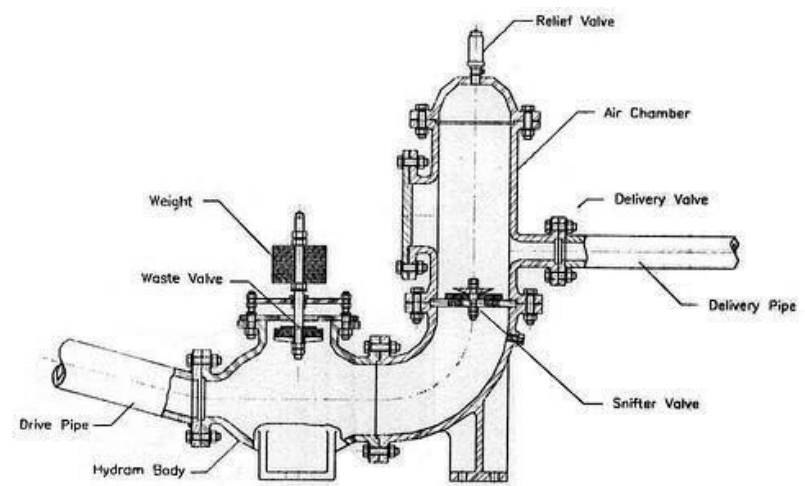

Fig. 3. Detail parts of hydraulic ram. [7]

Experimental work of the phenomena occurring in hydraulic ram throughout a single cycle work was studied based on the pressure changing then the single cycle of the pump was separated into three major phases: acceleration, pumping, and backflow [8]. They argued that the time period of the impulse valve movement was approximately a ten times lengthier than the delivery valve displacement period. Obviously, the real time will vary on the particulars of construction, specifically on the divergence in the masses of the valve related to the power of water flowing cross the delivery valve (9). The weight of the valve has the optimal discharge point and the proper mass setting be able to improve the efficiency up to $30 \%$ [10], [11]. Therefore, an adjustable weight of the valve was proposed in designing a hydraulic ram [12]. The pressure of water proportional to the length of the drive pipe, meanwhile it increased the pressure loss occurring [13]. Moreover, diameter of the drive pipe affected the quantity of water flowing through the impulse valves and efficiency of the pump [14]. A back-enlargement on the hydraulic ram model was proposed to decrease head loss and drag coefficient [15]. It would increase uniformity of the water flow then improving its overall performance. The optimal setting of the impulse valve was suggested at 68 beats per minute [16]. Different setting of the valve will affect the water flow rate, therefore it recommended to setting the impulse valve at $5 \mathrm{~mm}$ of its stroke [17]. The valve stroke have correlation to the pressure profile that take place in the hydraulic ram [18].

The present study was investigated the four models of the delivery valve: flat, membranes, sphere and half-sphere, which were operated in the hydraulic ram experimental setup. Performance of the pumps were measured experimentally. Further assessment was carried out on the real implementation of the unit for more consideration. The proper delivery valve shaped model was enhancing the overall performance of the pump.

\section{METHODS}

\section{A. Design of the delivery valve}

The schematic design of the study that has been conducted is shown in Fig. 4. This research has been conducted on the design and testing of the four delivery valve models, as shown in Fig. 7 to 10 .

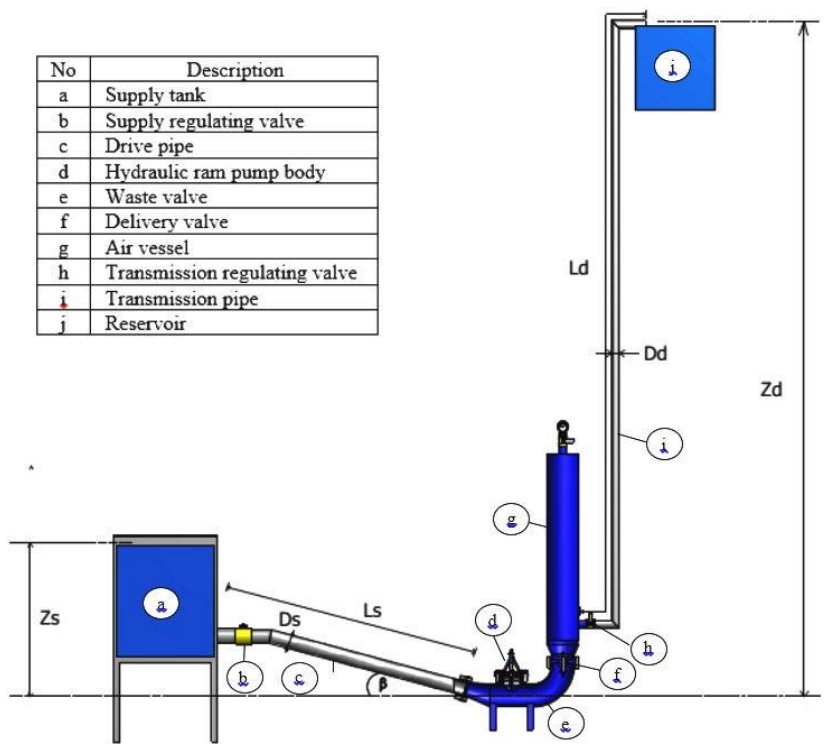

Fig. 4. Scheme of the hydraulic ram testing

\section{B. Design of the waste and delivery valves}

Design of the both valves were following the procedure. For fluid flow was compressed from point 1 to point 2, the continuity of equation is [19]: 
Where:

$$
Q=\mathrm{A}_{1} \cdot v 1=\mathrm{A}_{2} \cdot v_{2}
$$

$\mathrm{Q}=$ fluid flow $\left(\mathrm{m}^{3} / \mathrm{dt}\right)$

$\mathrm{A}_{1,2}=$ sectional area of the flow at point $1.2\left(\mathrm{~m}^{2}\right)$

$v_{1,2}=$ flow velocity at point $1.2(\mathrm{~m} / \mathrm{s})$

The head equation for a constant flow from point $\mathrm{s}$ to point $\mathrm{d}$ which is coupled with head losses is [20]:

$$
\begin{aligned}
& \underline{p}_{s} \quad v_{s}^{2} \quad \underline{p}_{d} \quad v d
\end{aligned}
$$

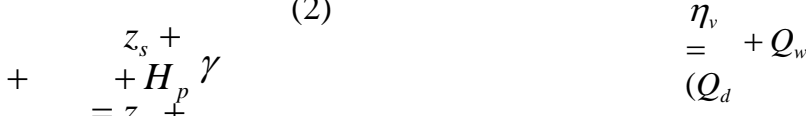

$$
\begin{aligned}
& 2 g=z_{d}+\gamma \\
& +{ }_{2 g}+H_{L}
\end{aligned}
$$

Where:

$\mathrm{Z}_{\mathrm{s}} \quad=$ static head of pump suction elevation (m)

$\mathrm{Z}_{\mathrm{d}} \quad=$ static head of pump discharge elevation (m)

$\mathrm{p}_{\mathrm{s}}=$ static head of pump suction pressure $\left(\mathrm{N} / \mathrm{m}^{2}\right)$

$\mathrm{p}_{\mathrm{d}}=$ static head of pump discharge pressure $\left(\mathrm{N} / \mathrm{m}^{2}\right)$

$\mathrm{v}_{\mathrm{s}}=$ dynamic head of fluid velocity at the suction $(\mathrm{m} / \mathrm{s})$

$\mathrm{v}_{\mathrm{d}}=$ dynamic head of fluid velocity at the discharge pump $(\mathrm{m} / \mathrm{s})$

$\mathrm{H}_{\mathrm{p}}=$ pump head (m)

$\mathrm{H}_{\mathrm{L}}=$ total head losses of pump piping installation system (m)

Friction losses in the pipe, then named major losses can be calculated with the equation:

$$
H_{L . M a}=f \frac{L v^{2}}{D 2 g}
$$

Where:
$\mathrm{f}=$ friction coefficient of the pipe
$\mathrm{D}=$ inner diameter of the pipe $(\mathrm{m})$
$\mathrm{L} \quad=$ length of the pipe $(\mathrm{m})$
$v=$ velocity of the flow $(\mathrm{m} / \mathrm{s})$
$\mathrm{g}=$ acceleration of the gravity $\left(\mathrm{m} / \mathrm{s}^{2}\right)$

While losses in pipe fittings or minor losses can be calculated with the equation:

$$
H_{L . M i}=K \frac{v}{2 g}
$$

Where $\mathrm{K}$ is the loss coefficient of pipe fittings.

Output power of the pump (Water Horse Power $=$ WHP) is the power generated by the pump, which can be expressed by the equation:

$$
W H P=\gamma \cdot Q \cdot H
$$

Where:

$$
\begin{array}{ll}
\text { WHP } & =\text { Water Horse Power (Watt) } \\
\gamma & =\text { fluid density }\left(\mathrm{N} / \mathrm{m}^{3}\right) \\
\mathrm{Q} & =\text { fluid flow rate in the pump }\left(\mathrm{m}^{3} / \mathrm{s}\right) \\
\mathrm{H} & =\text { total head of the pump }(\mathrm{m})
\end{array}
$$

Power available on the flow of water supplied to operate the pump proportional to the magnitude of volumetric rate

(discharge) of water supplied multiplied by the height of the supply. Where the water supply capacity is equal to the capacity of the waste water plus water pumping results. The pump works by exploiting the power available to drain some P-ISSN: 2579-597X, E-ISSN: 2579-5988

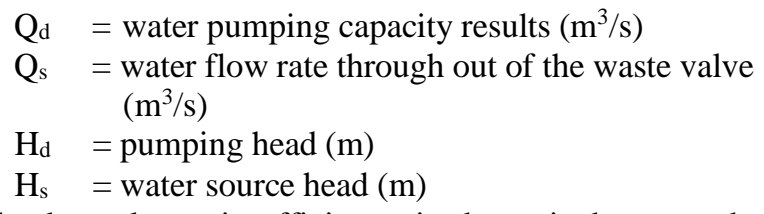

While the volumetric efficiency is the ratio between the discharge and the supply pump flow rate which can be expressed by the equation:

$$
)^{x 100 \%}-\frac{Q_{d}}{(7)}
$$

Water hammer is the pressure rise due to the stoppage of water suddenly. The amount of pressure that occurs due to water hammer is:

$$
P_{h}=\rho \cdot c \cdot v_{c}
$$

and

$$
c=\sqrt{E}
$$

Where:

$\mathrm{P}_{\mathrm{h}}=$ water hammer pressure $\left(\mathrm{N} / \mathrm{m}^{2}\right)$

$\mathrm{v}_{\mathrm{c}}=$ water velocity to close the waste valve $(\mathrm{m} / \mathrm{s})$

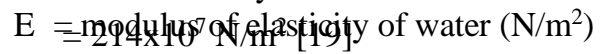

$\rho=$ density of water $\left(\mathrm{kg} / \mathrm{m}^{3}\right)$

$c=$ sound velocity in pipe $(\mathrm{m} / \mathrm{s})$

$$
=1440 \mathrm{~m} / \mathrm{s} \text { [21] }
$$

Bernoulli's equation can be derived from the water pressure acting on the valve when pressed, i.e.:

$$
\begin{gathered}
\text { Where: } \quad \mathrm{P}_{\mathrm{p}}=C_{f} \cdot \rho_{a} \cdot g\left(H_{s}-H_{L T}\right) \\
\mathrm{P}_{\mathrm{p}}=\text { water pressure at the valve }\left(\mathrm{N} / \mathrm{m}^{2}\right) \\
H_{L T}=\text { total head losses }(\mathrm{m}) \\
H_{S}=\text { head of water resources }(\mathrm{m}) \\
\rho_{a}=\text { density of water }\left(\mathrm{kg} / \mathrm{m}^{3}\right) \\
C_{f}=\text { flow coefficient }(0.25 \sim 0.35)
\end{gathered}
$$

The acceleration force of water in drive pipe can be derived from Newton's equation:

$$
F=m \underset{s}{ } \cdot a=\rho_{a} . A_{s} \cdot L_{s} \cdot d v
$$

Where: $F_{a}=$ accelerating force of water $(\mathrm{N})$

$m_{s}=$ mass of water accelerated $(\mathrm{kg})$

$a_{s}=$ acceleration of the water flow $\left(\mathrm{m} / \mathrm{s}^{2}\right)$

$\rho_{a}=$ density of water $\left(\mathrm{kg} / \mathrm{m}^{3}\right)$

$L_{S} \quad=$ length of pipe (m)

Then, acceleration of the flow in the drive pipe can be

$$
\begin{aligned}
& \text { governed by: } \\
& \text { Where: } \quad H_{s}-\frac{L}{D_{d}} \cdot \frac{v^{2}}{2 g}-\Sigma\left(K_{2 g}^{=}{ }_{g}^{=} a_{s}\right.
\end{aligned}
$$

\section{$f$}

of the water to a higher place. So the total efficiency of hydraulic ram is expressed as the D-Aubuission: 
$\begin{aligned} a_{s} & =\text { acceleration of the water flow }\left(\mathrm{m} / \mathrm{s}^{2}\right) \\ \mathrm{H}_{\mathrm{s}} & =\text { head of water resources }(\mathrm{m})\end{aligned}$

the pipe $(m) D_{s}$

$=$ diameter of the pipe $(\mathrm{m})$

$$
\eta_{t}=\frac{Q_{d} \cdot H_{d}}{\left(Q_{d}+Q_{w}\right) \cdot H_{s}} \times 100 \%
$$

Where: $v \quad=$ velocity of water flow $(\mathrm{m} / \mathrm{s})$

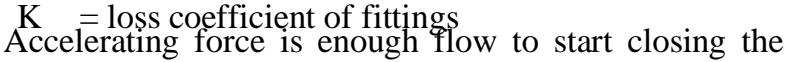

valve. Valve closes if the drag force and a compressive force equal to the weight of water in the valve [3]. 
International Journal of Engineering and Emerging Technology, Vol. 5, No. 1, January_June 2020

$$
F_{d}=C_{d} \cdot \rho \cdot A_{v} \cdot_{2 g}^{\underline{v}^{2}}
$$

Where:

$F_{d}=$ drag force on the valve $(\mathrm{N})$

$C_{d}=$ drag coefficient on the

valve

$=1.2$ for elliptic cylinder

$v_{s}=$ velocity of the water flow

(m/dt)

$A_{x}=$ cross sectional area of the valve $\left(\mathrm{m}^{2}\right)$

The acceleration period of the flow is [22]:

Where:

$$
\underline{v_{c}}-\underline{L}
$$

$$
T_{a}=K_{1 \cdot 2 g H_{s}}
$$

$T_{a}=$ acceleration time (s)

$v_{c}=$ water velocity to close the waste valve

$(\mathrm{m} / \mathrm{s})$

$\mathrm{L} \quad=$ length of the pipe $(\mathrm{m})$

$H_{s}=$ static head of the water source

(m)

$K_{1}=$ coefficient, a function of the speed ratio

The quantity of the water flow out through the valve:

Where:

$$
\left.A_{s} \cdot v_{c}^{2}\right] \underline{L}
$$

$$
V_{a}=K_{2} \cdot\left[\begin{array}{lll}
g & H
\end{array}\right.
$$

$V_{a}=$ volume of waste water exit valve $\left(\mathrm{m}^{3}\right)$

$A_{s}=$ cross sectional area of the pipe $\left(\mathrm{m}^{2}\right)$

$K_{2}=$ coefficient, as function of the speed ratio

$$
K_{1}=\frac{\ln _{\left[\begin{array}{c}
(1+a) \\
(1-a)]
\end{array}\right.}^{a_{a K_{1}}}}{\ln [\cos ]}
$$

Where: $a=v_{c}$

$$
K_{2}=a^{2}
$$

$\overline{v_{p p}}$
Pumping time is expressed [22]

$$
2 N L
$$

Where:

$$
T_{p} \quad c
$$

$T_{p}=$ pumping time (s)

${ }^{p}=$ amount of beats per second

The quantity of the water flow of each pumping cycle:

$$
\text { Where: } \quad V_{q}=\frac{V_{d \cdot v_{c}{ }^{2}}}{2 g \cdot H^{d}}
$$

$V_{q}=$ volume of each pumping cycle $\left(\mathrm{m}^{3}\right)$

$V_{d}=$ volume of discharge pipe $\left(\mathrm{m}^{3}\right)$

$H_{d}=$ pumping high $(\mathrm{m})$

The total cycle time $\left(\mathrm{T}_{0}\right)$ assuming zero recoil time:

$$
T_{o}=T_{a}+T_{P}
$$

The quantity of the water flow out through waste valve in $\mathrm{m}^{3} / \mathrm{s}$ [Young, 1997]:

$$
Q_{w}=\frac{V_{a}}{T_{o}}
$$

While the quantity of the water delivered to reservoir is:

$$
Q=\underline{T_{o}}
$$

Loss coefficient on the valve is:

$$
v_{P 0}=\sqrt{2 \cdot g \cdot H_{L W V}}
$$

Where:

$$
K=0.75+0.155\left({ }^{D_{p}}\right)^{2}
$$

$\mathrm{K}=$ loss coefficient of valve

$\mathrm{D}_{\mathrm{p}}=$ diameter of pipe valve seat $(\mathrm{m})$

$\mathrm{S}_{\mathrm{v}} \quad=$ step length of valve $(\mathrm{m})$

Step length can be calculated using equation [20]:

Where:

$$
L_{S C} \quad \pi x D_{k l} x
$$$$
=v_{\max }
$$

$L_{S C}=$ step length of valve $(\mathrm{m})$

$A_{b p}=$ area of pump body $\left(\mathrm{m}^{2}\right)$

$$
V_{b p}=\text { water velocity in pump body }(\mathrm{m} / \mathrm{dt})
$$

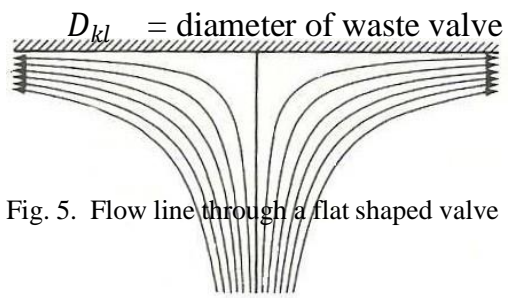

Water flow past the plate is shown in Fig. 5. A discontinuous potential flow theory which takes into account the separation of the flow created by Helmholtz in 1868 and Kirchoff in 1869. Completion of this free flow lines shown

in Figure 3, with flow lines that deviate from the plate edge constant speed. This gives the overall drag coefficient of 2.0, according to the results of the experiment. However, the

coefficient $\mathrm{k}$ is not known in advance, and must be adapted to the measurement data, so the theory that the free flow of results will be limited.

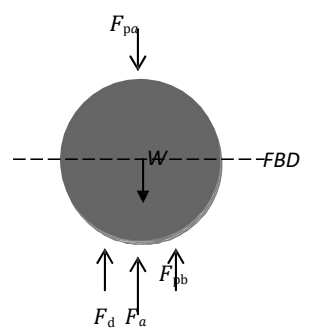

Fig. 6. Equilibrium of the forces on the sphere

$$
Q_{s}=Q_{w}+Q_{d}
$$

The relationship between the valve mass and the water flow velocity across the valve can be calculated using equation (Rajput, 2002): 
showhen the balance of the force on the sphere valve as $F_{a}+F_{d a}+W=F_{p}+F_{d b}$

8) This research has been made on the design of a variety shaped of the valves. Based on the calculation of initial design, the waste and the delivery valve models

$$
\frac{\mathfrak{v P O}^{2}}{2 g}=\frac{M}{\rho \cdot A_{v}}
$$

Where the water velocity flow through the waste valve is: has been designed including: flat, membrane, sphere and half-sphere models for the hydraulic ram. Models of the delivery valve has been created and tested as shown in Fig. 7 to 10 . With a flow rate of 1 litres/second of water sources then the drive pipe inner diameter was $38 \mathrm{~mm}$. Therefore, the waste valve

dimensions are:

- Valve hole diameter, $\mathrm{D}_{\mathrm{HKL}}=38 \mathrm{~mm}$ 
- $\quad$ Valve disk diameter, $\mathrm{D}_{\mathrm{DKL}}=58 \mathrm{~mm}$

- $\quad$ Step length (stroke), LSKL $_{\text {- }} 28 \mathrm{~mm}$

- Waste valve mass, $\mathrm{m}_{\mathrm{KL}}=220$ gram

In the other hand, the delivery valve dimensions are:

- Valve hole diameter, $\mathrm{D}_{\mathrm{HKT}}=40 \mathrm{~mm}$

- Valve disk diameter, DDKT $=62 \mathrm{~mm}$

- $\quad$ Step length (stroke), LSKL $_{\text {- }} 45 \mathrm{~mm}$

- Waste valve mass, $\mathrm{m}_{\mathrm{KL}}=1000$ gram

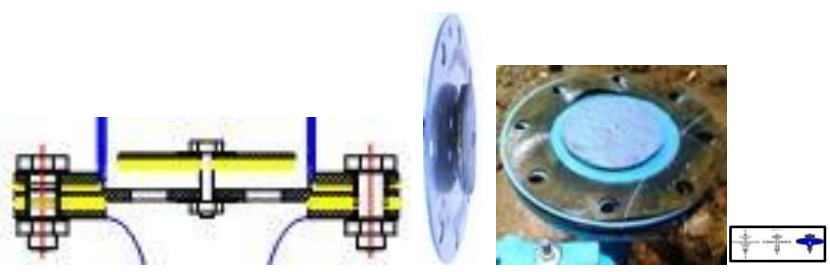

Fig. 7. Flat valve model

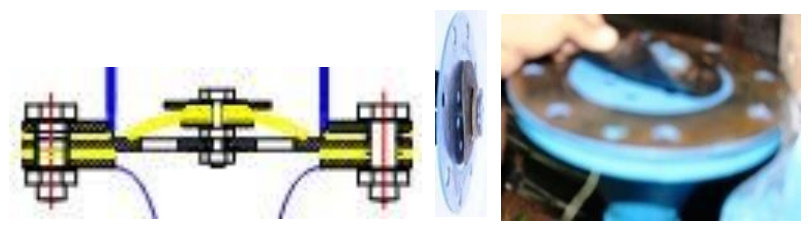

Fig. 8. Membrane valve model

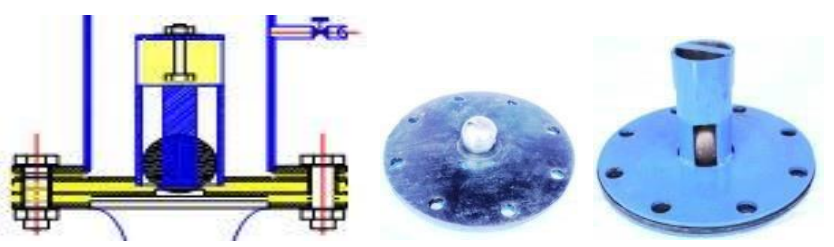

Fig. 9. Spherical valve model

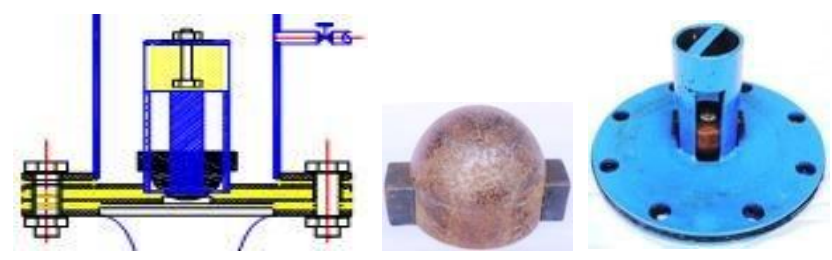

Fig. 10. Half Spherical valve model

\section{Testing Procedure}

The experimental works were carried out following the systematic procedure. The first model of delivery valve investigated was the flat model, then followed by the other model with similar steps. The height of the water source $\left(Z_{s}\right)$ was 4 meters, and the drive pipe length $\left(L_{s}\right)$ was 20 meters. Then, setup height delivery elevation $\left(Z_{d}\right)$ of 10 meters. The supply thank filled with water and kept on overflow by feeding continuously for constant level. The gate valve opened to drain the water from the tank through the drive pipe into the inlet of the pump. The pump cycle work have to commence by opening and closing the waste valve so that the pump can work automatically and continuously, then let the pump run for a while till in a stable work. Experimental data such as the time for which the volume of 20 liters of water out of the waste valve $\left(\mathrm{T}_{\mathrm{w}}\right)$, the time for a volume of 3 liters of water that comes out of the tap pipeline $\left(\mathrm{T}_{\mathrm{d}}\right)$ and press the pipe length $\left(\mathrm{L}_{\mathrm{d}}\right)$, the pressure on the manometer , and the frequency of the pump duty cycle (f) recorded. The previous steps repeated for three times. Whole the procedure steps were repeated for the other static delivery head $\left(Z_{d}\right)$ : 15,20 , and 25 meters.

\section{RESULTS AND DISCUSSION}

The experimental works have been done then the data of the test results obtained, then they were processed to get the performance of each model applied in the hydraulic ram. Based on the results of data processing the performance of the pump were presented as in Fig. 11 to 15, then comparison among the valve models have been identified.

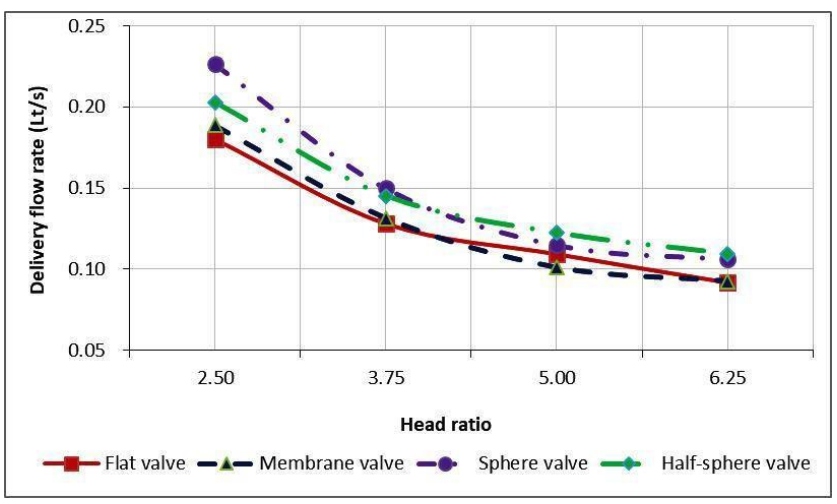

Fig. 11. Comparison of the results of pumping water discharge

Fig. 11 shows that the delivery discharge $\left(Q_{d}\right)$ of the hydraulic ram equipped with the sphere delivery valve model, in general, provided a greatest pumping discharge while the flat model performed the smallest pumping discharge. These were due to the flat disk of valve has larger drag coefficient than sphere therefore the flat valve smaller flow coefficient. In addition, the higher delivery head $\left(\mathrm{H}_{\mathrm{d}}\right)$ generated a smaller pumping discharge. It was agreeing to [14] results which stated that the delivery head and the pumping flow rate have inversely relationship.

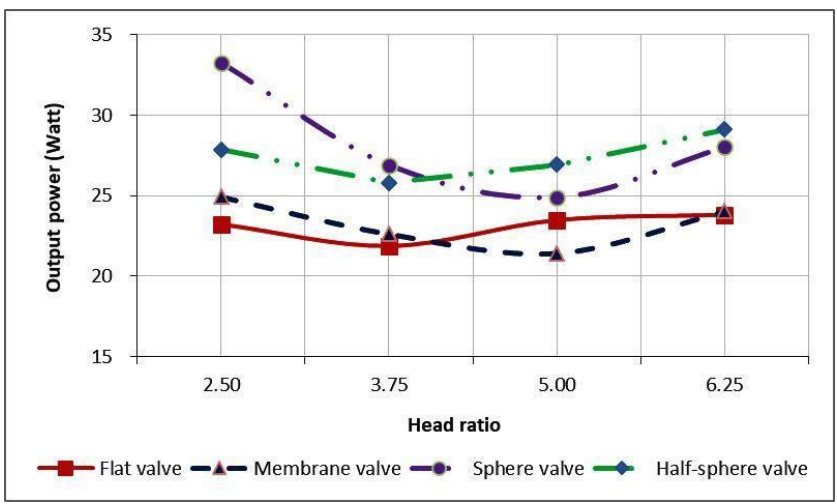

Fig. 12. Comparison of the output pumping power

Furthermore, the hydraulic ram with rounded shaped model of the delivery valve: sphere and half-sphere models offered a greater pumping power $\left(\mathrm{W}_{\mathrm{d}}\right)$ than the other models 
as shown in Fig. 12 because of the rounded objects are facing a lower head losses. Generally, the higher of the pumping head, the smaller the pump output power generated. This is because of the higher the pumping head have lengthier pipe which causing a higher head losses as well.

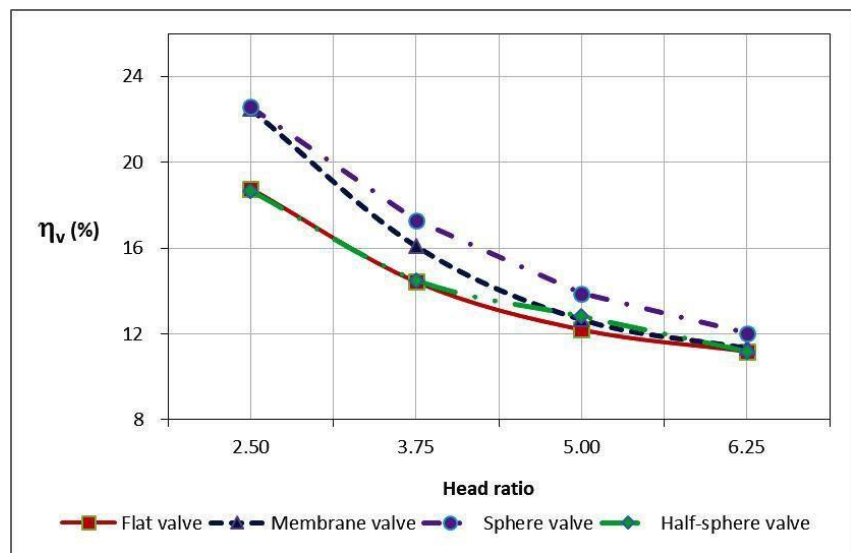

Fig. 13. Comparison of volumetric efficiency

Fig. 13 presents that the higher the pumping head or delivery head was resulting a smaller volumetric efficiency, because of it was accorded to the power formula at an equal power, the flow capacity and pumping head have inversely relationship. The sphere valve model performed the highest volumetric efficiency, followed by the membrane model. Interestingly, the half-sphere model offered a low volumetric efficiency because of its shape which was facing obstruction in its movement, where the edge of flat face of the valve disrupted to the valve housing.

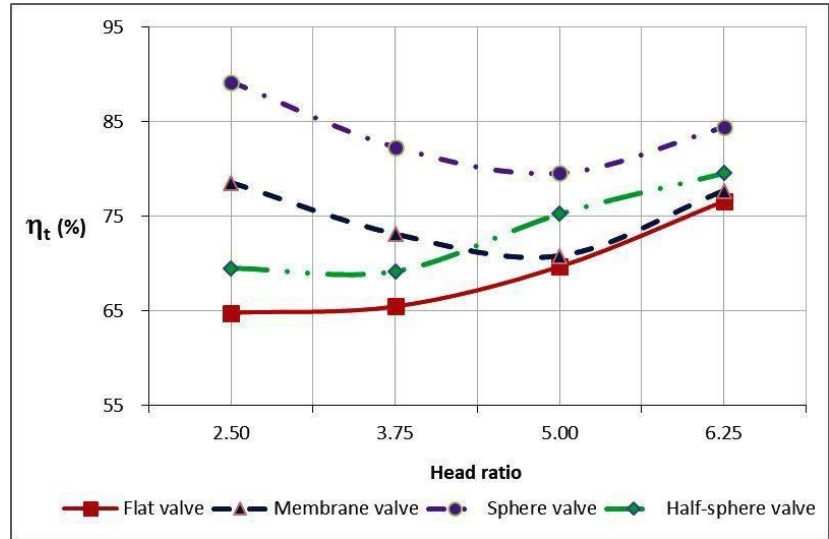

Fig. 14. Comparison of the total efficiency

Due to the sphere valve model performed the highest delivery flow rate and output pumping power, hence, it was offering the highest total efficiency $\left(\eta_{t}\right)$ as shown in Fig. 14. The efficiency was about of $65-80 \%$ which was in the range of [23] results, even the sphere valve model achieved more than the range for the lower delivery head. This model provided $10 \%$ up to $25 \%$ higher efficiency that the flat one.

Based on the comparison to other work results which were confirmed, it indicated that the results of the present work were valid or appropriate. Therefore, it can be stated that the shape of the valve affected the overall performance of the pump. However, it need further investigation for its implementation.

The sphere model of the delivery valve had been implemented instead of the flat model in the hydraulic ram that utilized to supply clean water in Catur village at Kintamani - Bangli. This pump was operated at 6 meters supply head and 110 meters delivery head. However, implementation of the sphere delivery valve model for a high delivery head experienced several disruptions. Among others, the valve could not closed tightly and the sphere of the valve generated a rough noise as a results of the sphere was spinning when they moved. Moreover, the sphere valve model was facing difficulty in built the sphere shape in fabrication stage. Therefore, for the moment, the membrane delivery valve model more preferred in implementation for the high delivery head. The reasons were simplicity in fabrication and it offered better performance than the flat model.

The implementation has faced obstruction in designing and setting of their valves because of there were not a specific guideline in literature. Due to large dimensions and work on high head, according the Pascal law the valves receives a large water hammer pressure proportional to the area of the valve disk, so it is a key parameter in designing a hydraulic ram. Although the pump operated well, but due to high head pressures and wide cross-sectional area resulted in a high surge pressure to the valves which affected the valves were broken. Therefore, it is necessary to find a solution to avoid the rapid deterioration of the delivery valve, once was by using a membrane valve which the valve encountered a relatively small force impact.

\section{CONCLUSION}

The experimental results of this preliminary study show that the shape of the delivery valve was affecting the hydraulic ram performance. The sphere shaped model of the delivery valve offered $10 \%$ up to $25 \%$ higher efficiency that the flat model for a low delivery head (up to 25 meters). However, this model still faced obstacles for implementation on a high delivery head. Therefore, to date, the membrane model was suggested for implementation on high delivery head in term of its simplicity and performance. Nevertheless, further research still desired for improving development's design of the sphere shaped model of the delivery valve.

\section{ACKNOWLEDGMENT}

The authors would like to express their gratitude to the Doctoral Study Program of engineering Science - Faculty of Engineering - University of Udayana.

\section{REFERENCES}

[1] G.D. Jennings, Hydraulic Ram Pumps, North Carolina: North Carolina Cooperative Extension Service, 1996.

[2] M. Logesh, P. Sakthivel, K.L. Sibi, and R. Siva, "Renewable energy hydram - a review", First International Conference on NexGen Technologies, Namakkal Dist. Tamilnadu-India, 5-6 January 2018, pp. 679-681. 
[3] T. Taye, "Hydraulic Ram Pump", Journal of the ESME, vol. 2, Addis Ababa, Ethiopia, Juli 1998.

[4] S.S. Mondol. 2017, "Design, manufacture and test a hydraulic ram", Research Gate Article, May 2017. https://www.researchgate.net/ publication/317031378.

[5] M. Inthachot, S. Saehaeng, J.F.J. Max, J. Müllerc, and W. Spreer, "Hydraulic ram pumps for irrigation in Northern Thailand", Elsevier B.V: in Agriculture and Agricultural Science Procedia, vol. 5, 2015, pp. 107-114.

[6] M. Suarda, and I G.K. Sukadana, "Penerapan Teknologi Pompa Hydram Untuk Meningkatkan Produktivitas Usaha Tani Sari Murni Banjar Kebon Jero", Report of 'Iptek bagi Masyarakat (IbM)', 2010.

[7] A.A. Tessema, "Hydraulic Ram Pump System Design and Application", ESME $5^{\text {th }}$ Conference on Manufacturing and Process Industry, Addis Ababa, Ethiopia, September 2000.

[8] W. Sobieski, D. Grygo, and S. Lipinski, "Measurement and analysis of the water hammer in ram pump", Indian Academy of Science: Sadhana, vol. 41, no. 11, 2016, pp. 1333-1347.

[9] R.N. Mbiu, S.M. Maranga, and M. Mwai, "Performance testing of hydraulic ram pump", Proceedings of the Sustainable Research and Innovation (SRI) Conference, 6 - 8 May 2015, pp. 6-8.

[10] M.N. Harith, R.A. Bakar, D. Ramasamy, and M. Quanjin, "A significant effect on flow analysis \& simulation study of improve design hydraulic pump", 4th International Conference on Mechanical Engineering Research (ICMER2017), IOP Conf. Series: Materials Science and Engineering, vol. 257, no. 012076, 2017.

[11] M.N. Harith, R.A. Bakar, D. Ramasamy, K. Kardigama, and M. Quanjin, "A study of waste and delivery valve design modification to the pump performance", iCITES 2018, IOP Conf. Series: Materials Science and Engineering, vol. 342, no. 012090, 2018.

[12] A. Rajaonison, and H.T. Rakotondramiarana, "Theoretical study of the behavior of a hydraulic ram pump with springs system", American Journal of Fluid Dynamics, vol. 9, no. 1, pp. 1-12.

[13] S.S. Sampath, S. Shetty, A.M. Pendanathu, W. Javaid, and M.C.P. Selvan, "Estimation of power and efficiency of hydraulic ram pump with re-circulation system", International Journal of Computer-aided Mechanical Design and Implementation, vol. 1, no. 1, 2015, pp. 718.

[14] H.T. Dhaiban, "Experimental study the performance of ram water pump", Energy Science, Reports on research projects, EUREKA: Physics and Engineering, no. 1, 2019, pp. 22-27.

[15] X. Guo, J. Li, K. Yang, H. Fu, T. Wang, Y. Guo, Q. Xia, and W. Huang, "Optimal design and performance analysis of hydraulic ram pump system", Proceeding of Institution of Mechanical Engineering 2018, Part A. J. Power and Energy, pp. 1-15.

[16] N. Mishra, E.I.B. Bhagat, and Y.K. Jyoti, "Effect of water hammering action on performance of hydraulic ram pump", International Journal of Scientific and Research Publications, vol. 8, no. 12, December 2018, pp. 396-399.

[17] F.S. Januddi, M.M. Huzni, M.S. Effendy, A. Bakri, Z. Mohammad, and Z. Ismail, "Development and testing of hydraulic ram pump (hydram): experiments and simulations", The Internacalvertional Fundamentum Sciences Symposium 2018. IOP Conf. Series: Materials Science and Engineering, vol. 440, no. 012032, 2018, pp. 1-9.

[18] G. Viccione, N. Immediata, R. Cava, and M. Piantedosi, "A preliminary laboratory investigation of a hydraulic ram pump", $M D P I$ Proceeding. The 3rd EWaS International Conference on "Insights on the Water-Energy-Food Nexus”, Lefkada Island, Greece, 27-30 June 2018, pp. 1-7.

[19] V.L. Streeter, and E.B. Wylie, Fluid Mechanics, $6^{\text {th }}$ edition, New York: McGraw-Hill Book Company, 1975.

[20] R.K. Rajput, A Textbook of Fluid Mechanics and Hidroulic Machines, S1 Version, New Delhi: S. Chad and Company Ltd, 2002.

[21] J.P. David, and H.W. Edward, Schaum's Outline of Theory and Problems of Fluid Mechanics and Hydraulics, Singapore: McGrawHill Book Company, 1985.

[22] B. Young, "Design of Homologous Ram Pump", Journal of Fluids Engineering, Transaction of the ASME, vol. 119, June 1997, pp.360365 .

[23] M. Chi, and P. Diemer, Hydraulic Ram Handbook, Bremen: Bremen Overseas Research and Development Association, 2002. 